\title{
Nuclear Factor-Erythroid-2-Related Factor 2 in Aging and Lung Fibrosis
}

\author{
Shobha M. Swamy, ${ }^{*}$ Namakkal S. Rajasekaran, ${ }^{\dagger}$ and Victor J. Thannickal ${ }^{*}$
}

From the Division of Pulmonary, Allergy and Critical Care, ${ }^{*}$ Department of Medicine, and the Center of Free Radical Biology, ${ }^{\dagger}$ University of Alabama School of Medicine, Birmingham, Alabama

Accepted for publication

February 22, 2016.

Address correspondence to

Victor J. Thannickal, M.D.,

Division of Pulmonary, Al-

lergy, and Critical Care Medi-

cine, University of Alabama at

Birmingham, Birmingham, AL

35294-2180. E-mail: vjthan@

uab.edu.

\begin{abstract}
Aging and age-related diseases have been associated with elevated oxidative stress, which may be related to increased production of reactive species and/or a deficiency in antioxidant defenses. The nuclear factor-erythroid-2-related factor 2 (Nrf2)-mediated antioxidant response pathway maintains cellular reduction-oxidation homeostasis by inducing the transcription of an array of cytoprotective genes. However, there is evidence of impaired Nrf2 response in aging contributing to age-related fibrotic diseases. Herein, we review mechanisms for the dysregulation of Nrf2 signaling in aging. This understanding will pave the way for the design of novel therapeutic strategies that restore Nrf2 signaling to reestablish cellular homeostasis in aging and age-related fibrotic diseases. (Am J Pathol 2016, 186: 1712-1723; http://dx.doi.org/10.1016/j.ajpath.2016.02.022)
\end{abstract}

Age-related diseases are increasing at a rapid rate worldwide in part related to increasing aging populations in developed countries. ${ }^{1}$ Fibrotic diseases, including those of the lung, are associated with aging. The mechanisms that predispose the aging lung to fibrosis are not known. Recent evidence suggests that the activation of nuclear factor-erythroid2-related factor 2 (encoded by NFE2L2 gene; Nrf2) may be dysregulated during the aging process and that this dysregulation may contribute to the development and progression of fibrosis. ${ }^{2} \mathrm{Nrf2}$ is a basic leucine zipper stress-responsive transcription factor that maintains cellular reduction-oxidation (redox) homeostasis. It regulates the transcription of $>200$ cytoprotective genes through antioxidant/electrophile response elements (ARE) in target gene promoters. ${ }^{3}$ The Nrf2 response pathway is an evolutionarily conserved adaptive mechanism to limit oxidative stress and maintain cellular/tissue homeostasis. The pathway may confer unique protection to the lungs because of the exposure of this organ to a variety of pro-oxidant environmental insults, including airborne toxins and infectious agents. In this article, we review the evidence for impaired Nrf2 activation in aging and the mechanisms for this deficiency. Improved understanding of altered Nrf2 activation in aging will pave the way for the design of novel therapeutic approaches for age-related fibrotic diseases.

\section{Nrf2-Keap 1 System}

Nrf2 belongs to a cap'n'collar family of proteins with conserved basic leucine zipper structure and seven functional Nrf2-ECH homology (Neh) domains, Neh1- $7^{4}$ (Figure 1). The Neh2 regulatory domain contains ETGE and DLG binding motifs separated by seven lysine residues. ${ }^{5,6}$ The ETGE and DLG binding motifs in Neh2 interact with Kelch-like ECHassociating protein 1 (Keap1), ${ }^{4}$ whereas the lysine residues are ubiquitinated leading to proteasomal degradation to regulate levels of Nrf2 at the post-translational level. ${ }^{6}$ The Neh4, Neh5, and Neh3 domains interact with coactivators for transactivation of Nrf2 target genes. ${ }^{7,8}$ The Neh1 domain facilitates dimerization with other transcription factors and DNA binding. ${ }^{9}$ The serine-rich Neh6 domain regulates the stability of Nrf2. ${ }^{10}$ A recent report reveals that retinoic $\mathrm{X}$ receptor $\alpha$ binds to the Neh7 domain and down-regulates Nrf2, suggesting a mechanism for Nrf2 repression independent of Neh2-Keap. ${ }^{11}$

Supported by NIH grants P01 HL114470, R01 AG046210, and R01 HL118067 (N.S.R.) and Veterans Administration Merit Award I01 BX003056 (V.J.T.).

A guest editor acted as the Editor-in-Chief for this manuscript. No one at the University of Alabama at Birmingham was involved in the peer review process or final disposition of this article.

Disclosures: None declared. 
A

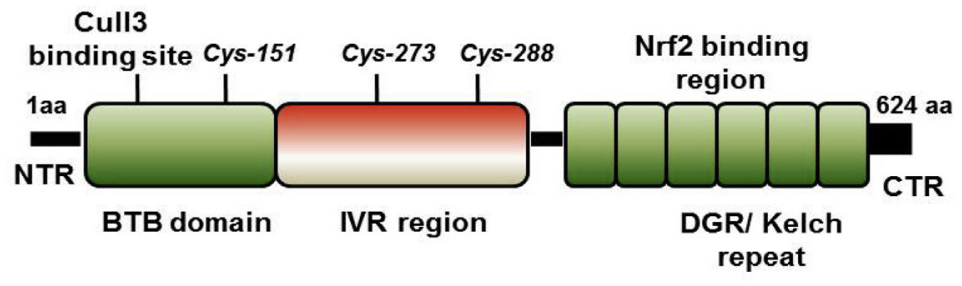

B
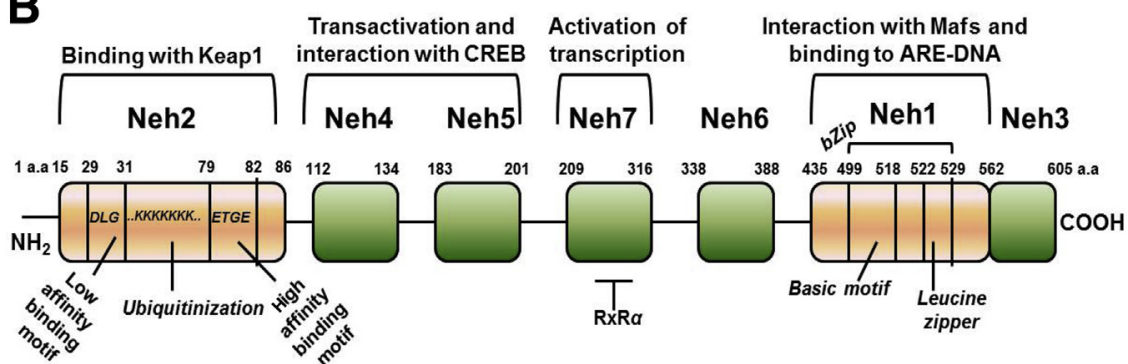

Figure 1 A: Schematic representation of the functional domains of Keap1. The $\mathrm{N}$-terminal region (NTR) contains the bric-à-brac (BTB) domain with cull3-binding site and reactive Cys-151 required for the activation of Nrf2; intervening region (IVR) region with two reactive Cys-278 and Cys-288 sites involved in stress sensing; and DGR/Kelch repeat domain, which interacts with Nrf2 and the C-terminal region (CTR). B: Schematic representation of the functional domains of Nrf2. Nrf2 contains seven Nrf2-ECH homology (Neh) domains. Neh1 interacts with Mafs and binds to antioxidant response element (ARE)-DNA; Neh2 binds to Keap1; Neh3, Neh4, and Neh5 are required for transactivation of Nrf2; Neh6 regulates stability of Nrf2; and Neh7 is required for activation of transcription. CREB, CAMP response element-binding protein; Maf, musculoaponeurotic fibrosarcoma.
Nrf2 is ubiquitously expressed in most eukaryotic cells. Its activation, under homeostatic conditions, is tightly restrained by the cytosolic repressor Keap. ${ }^{12}$ Keap 1 consists of five domains (Figure 1): the N-terminal broad complex, tramtrack and bric-à-brac domain, intervening region, a double glycine repeat, and a $\mathrm{C}$-terminal region. The bricà-brac domain contains the cysteine residue (Cys-151), ${ }^{13}$ and the intervening region contains an additional two reactive cysteine residues (Cys-273 and Cys-278) ${ }^{13}$ that are involved in stress sensing. Apart from these two domains, a double glycine repeat and $\mathrm{C}$-terminal region together form a $\beta$-propeller structure where Keap1 interacts with Nrf2. ${ }^{13}$

Various models have been proposed to explain the activation and stabilization of Nrf2. Of these, oxidation of Keap1 leading to the release of Nrf2 is the most widely studied mechanism (Figure 2). Under basal physiological conditions, Keap1 binds to Nrf2 in the cytoplasm and promotes ubiquitination by the Cullin E3 ligase, leading to subsequent degradation by the $26 \mathrm{~S}$ proteasome. In response to electrophilic or oxidative stress, oxidation of key cysteine residues (Cys-151, Cys-273, and Cys-278) in Keap1 alters its conformation and,

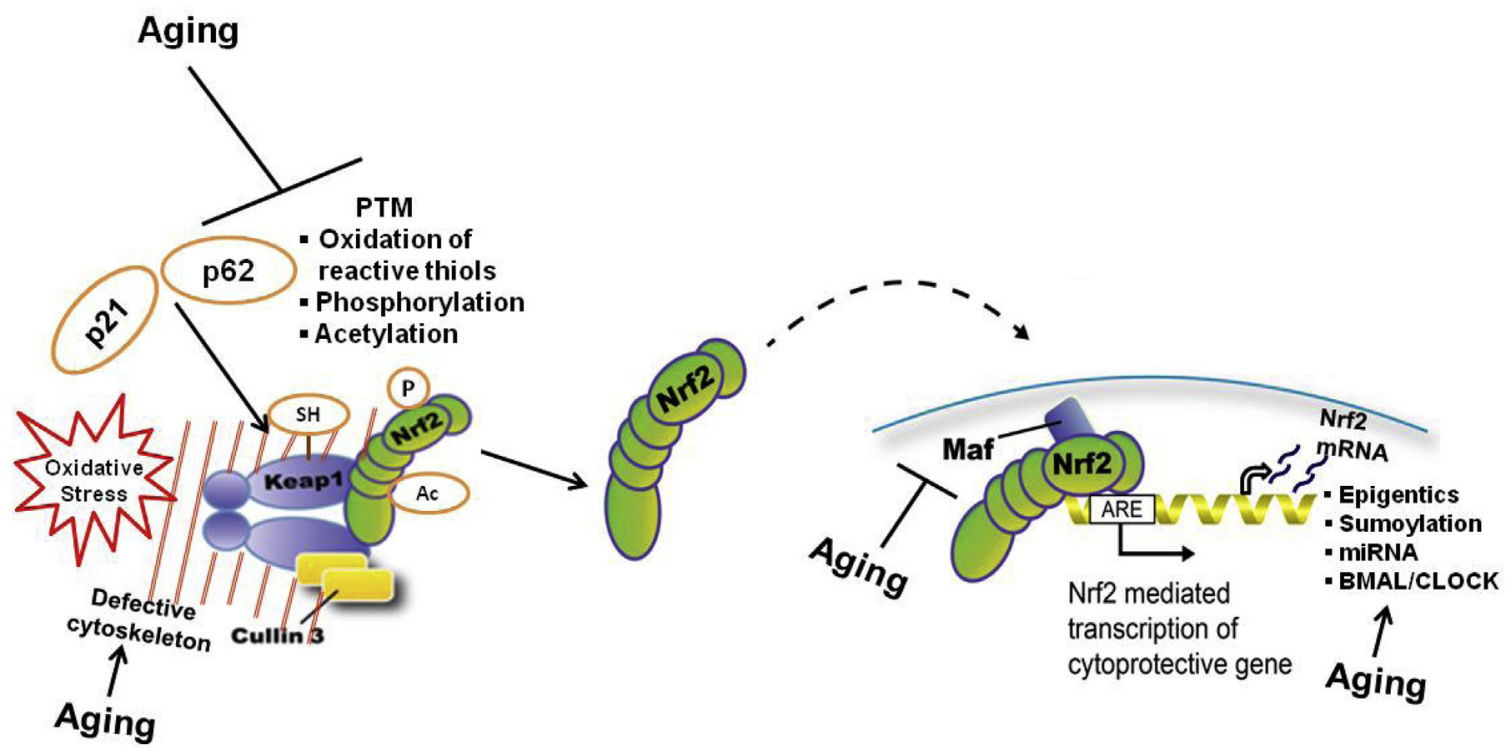

Figure 2 Proposed mechanisms for altered Nrf2 signaling in aging. Under homeostasis, Nrf2 is maintained at low levels by the binding of Nrf2 to Keap1, which facilitates ubiquitination by Cullin E3 ligase and subsequent proteosomal degradation by the $26 \mathrm{~S}$ proteasome. Under conditions of oxidative stress, oxidative modification of cysteines in Keap1 leads to conformational changes that release Nrf2; this allows Nrf2 to translocate to the nucleus to transcribe several cytoprotective genes. In aging or cellular senescence, alterations in post-translational modifications (PTMs) involving oxidation of sulfhydryl groups $(\mathrm{SH})$ in cysteine residues in Keap1 and phosphorylation (P) and/or acetylation (Ac) of Nrf2 modulates release/activation of Nrf2. In addition, impaired autophagy (eg, p62 aggregation), p21 and cytoskeletal alterations may impair cytoplasmic-nuclear trafficking. In the nucleus, dysregulation in binding of cofactors (Maf and BTB domain and CNC homolog 1), epigenetics, sumoylation, miRNAs, and BMAL/CLOCK may contribute to age-related impairment in Nrf2 activation. BMAL/CLOCK, brain and muscle arnt-like protein-1/circadian locomotor output cycles kaput; Maf, musculoaponeurotic fibrosarcoma. 
Table 1 Nrf2-Responsive Genes that Regulate Antioxidant Defense and Metabolism

\begin{tabular}{|c|c|c|}
\hline Gene & Protein & Function \\
\hline GSTA1 & Glutathione S-transferase A1 & $\begin{array}{l}\text { Detoxifies and metabolizes electrophilic compounds; metabolizes bilirubin and } \\
\text { certain anticancer drugs; also displays glutathione peroxidase activity. }{ }^{16}\end{array}$ \\
\hline GSTM1 & Glutathione S-transferase M1 & Detoxifies and metabolizes electrophilic compounds. ${ }^{16}$ \\
\hline NQ01 & $\mathrm{NAD}(\mathrm{P}) \mathrm{H}$ quinone oxidoreductase 1 & $\begin{array}{l}\text { Reduces quinones to hydroquinones and prevents one-electron reduction of } \\
\text { quinones that would generate free radicals. }{ }^{17,18}\end{array}$ \\
\hline HMOX1 & Heme oxygenase 1 & Cleaves heme to produce biliverdin during heme catabolism. ${ }^{19}$ \\
\hline ACOT7 & Acyl-CoA thioesterase 7 & $\begin{array}{l}\text { Catalyzes the hydrolysis of palmitoyl-CoA and other long-chain fatty acids to form } \\
\text { free fatty acid and CoA. }{ }^{21}\end{array}$ \\
\hline G6PD & Glucose-6-phosphate dehydrogenase & $\begin{array}{l}\text { Generates NADPH in the pentose phosphate pathway; maintains cellular } \\
\text { glutathione reduction-oxidation status. }{ }^{17}\end{array}$ \\
\hline IDH1 & Isocitrate dehydrogenase 1 & $\begin{array}{l}\text { Catalyzes the oxidative decarboxylation of isocitrate to } \alpha \text {-ketoglutarate, using } \\
\text { NADP }^{+} \text {as a cofactor. }{ }^{22}\end{array}$ \\
\hline GCLC & $\begin{array}{l}\text { Glutamate-cysteine ligase catalytic } \\
\text { subunit }\end{array}$ & $\begin{array}{l}\text { Catalytic subunit of the enzyme responsible for the rate-limiting step in synthesis } \\
\text { of cellular glutathione. }{ }^{25}\end{array}$ \\
\hline GLCM & $\begin{array}{l}\text { Glutamate-cysteine ligase modifier } \\
\text { subunit }\end{array}$ & $\begin{array}{l}\text { Modifier subunit of the enzyme responsible for the rate-limiting step in synthesis } \\
\text { of the cellular glutathione. }\end{array}$ \\
\hline GPX & Glutathione peroxidase & Detoxification of hydrogen peroxide and an important cellular antioxidant. ${ }^{17}$ \\
\hline PRDX1 & Peroxiredoxin 1 & Reduces peroxides, regulates cellular concentrations of hydrogen peroxide. ${ }^{26}$ \\
\hline TRX1 & Thioredoxin 1 & $\begin{array}{l}\text { Reversible oxidation of active center allows participation in dithiol-disulfide } \\
\text { exchange reactions; reduces sulfenic acid in proteins. }{ }^{27}\end{array}$ \\
\hline
\end{tabular}

Nrf2, nuclear factor-erythroid-2-related factor 2.

thereby, destabilizes the Keap1-Nrf2 complex, causing it to dissociate. ${ }^{14}$ Release of Nrf2 is followed by protein kinasemediated phosphorylation at Ser-40 and translocation to the nucleus. ${ }^{15}$ Once in the nucleus, Nrf2 binds to ARE/electrophile response elements in the promoter regions of target cytoprotective genes and regulates their transcription.

\section{Nrf2 in Cellular Redox Homeostasis}

The protective effect of Nrf2 is largely attributed to its ability to transactivate genes that are responsible for antioxidative defense, anti-inflammatory actions, repair functions, and metabolic regulation (Tables 1 and 2). Stressdependent induction of Nrf2 signaling directly regulates the transcription of several antioxidant enzymes, including glutamate cysteine ligase (GCL; both GCLC and GCLM subunits), ${ }^{25}$ glutathione S-transferase $(G S T),{ }^{17}$ glutathione peroxidase $(G P x),{ }^{17}$ glutathione reductase $(G R)$, heme oxygenase-1 (HMOX1), and $\operatorname{NADP}(\mathrm{H})$ quinone oxidoreductase 1 (NQO1). GCL, GST, GPx, and GR are involved in glutathione (GSH) biosynthesis and its recycling. ${ }^{32} \mathrm{GSH}$ minimizes cellular stress by scavenging free radicals and

Table 2 Nrf2-Responsive Genes that Regulate Inflammation

\begin{tabular}{|c|c|c|}
\hline Gene & Protein & Function \\
\hline IL1B & IL-1 $\beta$ & Regulates immune and inflammatory responses to infections. ${ }^{28}$ \\
\hline IL6 & IL-6 & Acts as both a proinflammatory cytokine and an anti-inflammatory myokine. ${ }^{28}$ \\
\hline IL12p40 & IL-12 p40 & $\begin{array}{l}\text { Acts as a chemoattractant for macrophages and promotes the migration of bacterially } \\
\text { stimulated dendritic cells. }{ }^{28}\end{array}$ \\
\hline TNFA & Tumor necrosis factor $\alpha$ & $\begin{array}{l}\text { Responsible for a diverse range of signaling events within cells, leading to necrosis or } \\
\text { apoptosis. }{ }^{28}\end{array}$ \\
\hline iNOS & Nitric oxide synthase 2 , inducible & $\begin{array}{l}\text { A reactive free radical that acts as a biological mediator in several processes, including } \\
\text { neurotransmission, antimicrobial and antitumoral activities. }{ }^{30}\end{array}$ \\
\hline FGF7 & Keratinocyte growth factor & Regulates gene expression and inflammation in wound healing. ${ }^{31}$ \\
\hline CCL2 & Monocyte chemotactic protein 1 & Key chemokine that regulates migration and infiltration of monocytes/macrophages. ${ }^{30}$ \\
\hline
\end{tabular}

Nrf2, nuclear factor-erythroid-2-related factor 2. 
serves as source of reducing equivalents to maintain cellular redox balance. Nrf2-induced GSH biosynthesis has been implicated in development of cellular resistance to druginduced apoptosis ${ }^{33}$; in contrast, depletion of GSH by cytotoxic electrophiles increases oxidative stress. ${ }^{34}$ Circadian regulation of Nrf2 is controlled by BMAL/CLOCK transcription factors and mediates rhythmic control of GSH levels as well as diurnal variation in drug-induced toxicity. ${ }^{35,36}$ It has been reported that age-dependent alterations in the reduced versus oxidized ratio of glutathione (GSH/GSSG) significantly affects the redox state of the tissues. ${ }^{37}$ These studies, although not definitive, suggest that decreases in total GSH and/or reduced/oxidized ratio of GSH may be mediated, in large part, by the impaired activation of $\mathrm{Nrf} 2$ in aging.

Heme oxygenase 1 (HO-1; encoded by HMOXI gene) catalyzes the breakdown of heme to carbon monoxide, free iron, and biliverdin. Biliverdin in the presence of biliverdin reductase gets reduced to bilirubin, ${ }^{38}$ which possesses antioxidative properties. ${ }^{38}$ In addition, innate immunity and wound healing processes may be modulated by the up-regulation of HO-1 by Nrf2. ${ }^{39}$ NQO1 catalyzes the twoelectron reduction of highly reactive quinones to hydroquinones. In response to genotoxic stress, Nrf2-mediated up-regulation of NQO1 reduces the formation of free radicals by redox cycling of quinones and may mediate tumor suppressor activities, in part by stabilizing $\mathrm{p} 53 .{ }^{18}$ Activated Nrf2 modulates the transcription of other antioxidant genes such as superoxide dismutase, catalase, thioredoxin reductase, and peroxiredoxin. Recently, it has been recognized that Nrf2 regulates inflammation and promotes resolution via cross talk with NF- $\kappa \mathrm{B} .{ }^{29}$ In endothelial cells, modulation of HO-1 activity by Nrf2 inhibited NF- $\kappa \mathrm{B}-$ mediated transcription of vascular cell adhesion molecule-1 and E-selectin. ${ }^{40}$ Induction of Nrf2 signaling in mouse peritoneal macrophages reduces lipopolysaccharide-mediated induction of cyclooxygenase 2 , tumor necrosis factor- $\alpha$, and IL-1 $\beta$ expression. ${ }^{41}$ In response to acute lung injury, deletion of Nrf2 was associated with impaired resolution of inflammation. ${ }^{42}$

In addition to its antioxidant defense anti-inflammatory actions, Nrf2 contributes to cytoprotection by repair and removal of damaged macromolecules. Activation of $\mathrm{Nrf} 2$ mediates the clearance of inclusion bodies formed by damaged and misfolded proteins through proteosomal degradation. ${ }^{43}$ As an adaptation to hydrogen peroxide and menadione-induced oxidative stress, up-regulation of Nrf2 induces the expression of $26 \mathrm{~S}$ proteosome and Pa28 $\alpha \beta$ regulator. ${ }^{44} \mathrm{Nrf} 2$-induced proteosomal activity and expression of $20 \mathrm{~S}$ and $19 \mathrm{~S}$ proteosome subunits have been demonstrated in murine liver. ${ }^{45}$ Induction of the DNA glycosylase, 8-oxoguanine glycosylase, expression via Nrf2 signaling has been shown to inhibit reactive oxygen species (ROS)-mediated DNA damage in breast cancer. ${ }^{46}$

Nrf2 signaling regulates several metabolic pathways and mitochondrial function. Activation of $\mathrm{Nrf} 2$ induces the expression of various genes and enzymes catalyzing the rate-limiting steps in carbohydrate, lipid, and protein biosynthesis. ${ }^{43}$ Constitutive activation of Nrf2 in mouse embryonic fibroblast enhances the efficiency of oxidative phosphorylation, ATP levels, and mitochondrial membrane potential. ${ }^{47}$ Deficient expression of Nrf2 has been reported to alter respiration and ATP production through decreased fatty acid oxidation in mitochondria of liver and heart. ${ }^{48}$

Although Nrf2-mediated protection against inflammation and/or oxidative stress by up-regulation of cytoprotective genes is well documented, the precise role of $\mathrm{Nrf} 2$ in the context of aging and age-related diseases remains elusive. Thus, understanding the molecular mechanisms of Nrf2 signaling in the context of aging is crucial in the development of Nrf2-based therapeutics.

\section{Nrf2 in Aging}

Increased ROS/reactive nitrogen species and the resultant oxidative stress-induced macromolecular damage is a hallmark of aging and age-related diseases. ${ }^{49,50}$ Although ROS/ reactive nitrogen species mediate redox signaling in normal physiology, ${ }^{51}$ sustained and chronic oxidative stress likely contributes to the acceleration of aging and/or age-related diseases. Recent reports in mouse transgenic models suggest that oxidative stress may contribute to age-related pathology, while not altering longevity. ${ }^{52,53}$ Thus, a better understanding of the redox imbalances in specific agerelated diseases will aid in the development of more targeted therapies for these diseases.

A few studies report functional Nrf2 signaling in promoting healthy aging with improved life span. ${ }^{54,55}$ The activation of Nrf2 signaling by a Keap1 loss-of-function mutation augments tolerance to oxidative stress and confers increased lifespan in Drosophila. ${ }^{55}$ Nrf2-dependent signaling has been reported to restore the loss of proteostasis and prevent premature aging in Drosophila. ${ }^{56}$ Furthermore, Nrf2 signaling has been documented to confer resistance to oxidative stress and promote healthy aging in Caenorhabditis elegans. ${ }^{57,58}$

Reduced activation of Nrf2 in aging has been reported to be associated with various chronic diseases, such as progressive respiratory disease, neurodegeneration, and inflammatory disorders. ${ }^{59}$ Age-dependent decline in the levels and/or activation of Nrf2 is accompanied by reduced expression of cytoprotective genes and increased susceptibility to oxidative injury. ${ }^{60}$ Age-associated decreases in total and nuclear Nrf2 protein levels have been shown to reduce the expression of antioxidant genes $H M O X 1, N Q O 1$, and $G C L C$ in the liver and heart of aging animals. ${ }^{61,62} \mathrm{We}$ have demonstrated a marked reduction in the capacity for Nrf2 activation and ARE-regulated gene expression in cellular models of senescence, ${ }^{2}$ although senescence-associated mechanisms for the diminished activation of Nrf2 are unclear. Current working models of how aging and senescence may alter the stabilization and/or activation of Nrf2 suggest 
that this impairment may occur at various levels, including Keap1 dependent and independent pathways (Figure 2).

\section{Keap1-Dependent Mechanisms}

Keap1 is a well-known cytoplasmic repressor of Nrf2 under basal physiological conditions. ${ }^{12}$ Oxidative stress or electrophile-mediated conformational changes in Keap1 because of oxidation of reactive thiols on cysteine residues (Cys-151, ${ }^{14}$ Cys-273, and C-278 ${ }^{14}$ ) weaken its interaction with $\mathrm{Nrf} 2$, thereby promoting subsequent translocation of Nrf2 into the nucleus. ${ }^{14}$ It is possible that other posttranslational modifications might stabilize the interactions between Keap1 and Nrf2 during aging, thus decreasing redox sensing by Keap1. In addition to the known mechanism involving oxidation of cysteine residues, a noncanonical regulatory mechanism involving Keap1 also regulates Nrf2 activity. Scaffolding of Keap1 through its double glycine repeat domain to the actin cytoskeleton sequesters Nrf2 and promotes proteasomal degradation, whereas disruption of the actin cytoskeleton-Keap1 interaction releases Nrf2 and promotes its nuclear translocation. ${ }^{63}$ Alterations in actin cytoskeletal regulation with aging would be expected to contribute to dysregulated Nrf2 responses. ${ }^{64}$ Further studies of Nrf2 activation and cytoskeletal regulation in aging are warranted.

The cyclin-dependent kinase inhibitor, p21, has been shown to activate Nrf2. KRR motifs of p21 directly interact with the DLG and ETGF motifs of the Neh1 functional domain of Nrf2, thereby competing with Keap1 for Nrf2 binding and inhibiting Keap1-mediated ubiquitination of Nrf2. ${ }^{65}$ The reasons for a deficiency in Nrf2 activation with cellular senescence associated with high levels of p21 are currently unknown.

Another noncanonical, Keap1-dependent mechanism for Nrf2 activation may involve impaired autophagy, which has been associated with aging. ${ }^{66}$ Decreased autophagy resulting in accumulation of p62, an autophagy cargo protein, would be predicted to activate Nrf2 by binding/sequestering Keap1, thus limiting its inhibitory interaction with Nrf2. ${ }^{67}$ However, although age-dependent increases in p62 levels may occur, it has been reported to self-aggregate in aging, leading to decreased activity. ${ }^{68}$ This represents one potential mechanism for the paradoxical impairment of Nrf2 signaling with aging.

\section{Keap1-Independent Mechanisms}

Keap1-independent mechanisms of Nrf2 activation involve several reported post-translational modifications, including phosphorylation, ${ }^{15}$ acetylation, ${ }^{69,70}$ and interactions with cofactors, such as Maf, ${ }^{71}$ ATF $4{ }^{72}$ and CREB ${ }^{73}$ Kinasemediated phosphorylation of Ser-40 residue on Nrf2 is reported as a requisite for the activation and nuclear translocation of Nrf2. ${ }^{15}$ Activation of protein kinase C (PKC) phosphorylates Ser-40 residue on the Neh2 domain of Nrf2, resulting in the release and nuclear translocation of Nrf2. ${ }^{74}$
Various isoforms of PKC and atypical PKC have been documented to be involved in phosphorylation of Nrf2. ${ }^{15,75}$ Phosphatidylinositol 3-kinase-mediated phosphorylation of Nrf2 and its dissociation, nuclear translocation, and subsequent induction of antioxidants have been shown in human neuroblastoma cells. ${ }^{76}$ In addition to the involvement of PKC and phosphatidylinositol 3-kinase in the activation of Nrf2, accumulating evidence suggests a role for mitogenactivated protein kinases ${ }^{19,77,78}$; however, some reports suggest negative regulation of $\mathrm{Nrf} 2$ by these protein kinase pathways. ${ }^{79}$ For example, extracellular signal regulated kinase $1 / 2$ signaling cascades have been shown to increase the activation/stabilization of Nrf2, leading to induction of cytoprotective genes. ${ }^{77}$ Activation of $\mathrm{p} 38$ mitogen-activated protein kinase and Janus kinase has also been implicated in the activation and nuclear translocation of Nrf2. ${ }^{19,78}$ In contrast, phosphorylation of tyrosine residues (Tyr-568) on Nrf2 by glycogen synthetase kinase $3 \beta$ activated Fyn has been shown to promote nuclear export and degradation of $\mathrm{Nrf} 2{ }^{79}$

Acetylation and deacetylation of Nrf2 promote nuclearcytoplasmic shuttling and regulation of its transcriptional activity. ${ }^{69}$ Acetylation of lysine residues in Nrf2 enhances Nrf2-DNA binding and transcription of target genes. The acetylation of lysine residues in the Neh1 domain of Nrf2 by p300/CBP augments promoter-specific DNA binding in response to arsenite-mediated oxidative stress. ${ }^{70}$ Mutating Lys-588 and Lys-591 of Nrf2 impairs Nrf2-dependent gene transcription by distorting the transcription-activating effect of CREB-binding protein. ${ }^{69}$ Age-related changes in activities of protein kinases or acetyltransferases/ deacetylases may lead to impaired Nrf2 regulation. Agerelated changes in the expression and activity of PKC, ${ }^{80}$ and phosphatidylinositol 3-kinase ${ }^{81}$ have been reported in both aging animal models and humans. Therefore, further studies on these altered phosphorylation and acetylation signaling mechanisms in the context of aging may provide additional insights into dysregulated Nrf2 responses in ageassociated disorders.

Several Nrf2 cofactors and transcriptional regulators that control its activity both positively and negatively have been described. ${ }^{71,72,82}$ Bach1 is reported to be a negative regulator of Nrf2 signaling within the nuclear compartment. ${ }^{82}$ Transient or stable binding of Bach1 to ARE in specific promoters has been shown to repress tBHQ-induced Nrf2-ARE activation. ${ }^{82}$ An age-related increase in Bach1 binding to the ARE of the GCLC promoter competed with Nrf2-ARE binding in the liver of old mice. ${ }^{83}$ On the other hand, dimerization of transcriptional coactivator Mafs with Nrf2 facilitates stable Nrf2-ARE interaction and enhances the transcription of cytoprotective genes. ${ }^{71}$ Although no age-related changes in the basal expression of Mafs has been reported, reduced Nrf2 responses have been attributed to a failure in the activation of Mafs during aging in Drosophila; however, overexpression of Mafs is capable of restoring this aging-associated decline of Nrf2-responsive 
genes. ${ }^{84}$ The transcription factor, ATF4, is another known positive regulator of Nrf2 signaling. ${ }^{72}$ Although the heterodimerization of ATF4 with Nrf2 increases the AREmediated HO-1 expression, ${ }^{85}$ a decline in ATF4 levels in various tissues of aging mice ${ }^{86}$ is likely to be associated with impaired Nrf2 signaling. Regulation of the Nrf2 pathway by the transcriptional regulator, protein deglycase DJ-1 (alias PARK7), has been reported ${ }^{87}$; overexpression of DJ-1 resulted in the increased expression of Nrf2 protein levels, nuclear translocation, and enhanced ARE-mediated Trx 1 gene expression. ${ }^{87}$

Keap1-independent mechanisms of Nrf2 activation may also involve the E3 ubiquitin ligase system. ${ }^{88} \mathrm{Hrd1}$, an E3 ubiquitin ligase of the endoplasmic reticulum stress pathway, has been reported to target the Neh4 and Neh5 domain of $\mathrm{Nrf} 2$ for ubiquitination and degradation of Nrf2. ${ }^{89}$ Up-regulation of Hrd1 suppresses Nrf2 expression and Nrf2-mediated antioxidant defense in human cirrhotic liver. ${ }^{89}$ Phosphorylation of serine residues (Ser-334 and Ser338 of DSGIS motif) in the Neh6 domain of Nrf2 by glycogen synthetase kinase $3 \beta$ also promotes degradation of Nrf2 by $\beta$-TrCP, an adaptor protein of Cull3 ligase system. ${ }^{90}$ The role of these E3 ubiquitin ligases in context of aging and fibrosis is not well understood, although a general decline in the function of the ubiquitin-proteosomal system with aging is well appreciated.

Post-translational modifications mediated by AMPK, ${ }^{91}$ sumoylation, ${ }^{92}$ and miRNAs ${ }^{93}$ are also known to regulate Nrf2 signaling. In endothelial cells, activation of AMPK stimulates the expression of the antioxidant enzyme HO-1 through Nrf2 signaling. ${ }^{91}$ In the unfolded protein response, activation of AMPK up-regulates Nrf2/HO-1 signaling in mouse embryonic fibroblasts. ${ }^{94}$ Defining the precise role of AMPK in age-related regulation of Nrf2 signaling has the potential for clinical translation. Sumoylation has been reported to be involved in regulating Nrf2 signaling. ${ }^{92}$ Murine macrophages (RAW cells) and hepatocytes isolated from lipopolysaccharide-treated mice showed decreased Nrf2 sumoylation, which reduced Nrf2ARE signaling through altered $\mathrm{Nrf} 2 / \mathrm{MafG}$ interaction. ${ }^{92}$ Although age-related changes in the sumoylation of proteins have been reported, ${ }^{95}$ the mechanisms of how sumoylation of Nrf2 regulates its activity remain unclear.

Recent studies also suggest a role for epigenetics ${ }^{96}$ in the regulation of Nrf2. The increased expression of Keap1 protein because of demethylation of the Keap1 promoter region leads to decreased stability of Nrf2 and results in a failure of the antioxidant response in age-related cataracts. ${ }^{96}$ The miRNAs, miR-144, miR-27a, and miR-153, have been reported to regulate $\mathrm{Nrf} 2$ gene expression. ${ }^{93,97}$ In addition, miRNAs are also known to target other Nrf2 regulators and alter Nrf2 activation. ${ }^{98}$ Although age-related changes in the expression of miRNAs have been reported ${ }^{97}$ investigating their role in regulating Nrf2 activation and downstream transcriptional responses in cellular/animal models of aging requires further investigation.
Additional epigenetic mechanisms involving DNA methylation and histone modifications may regulate Nrf2 activity. Nrf2 gene promoter methylation associated with methyl-CpG-binding protein 2 and histone modifications epigenetically down-regulated the expression of Nrf2 in murine tumor models. ${ }^{99}$ Genetic disruption of molecular clocks alters the rhythmic activation of Nrf2 and potentiates fibrosis in a lung injury model. ${ }^{35}$ Although age-related declines in circadian rhythms are known to occur, ${ }^{100}$ it is not known whether changes in the expression of clock genes and altered circadian rhythms lead to increased susceptibility to age-related lung fibrosis through impaired activation of Nrf2.

\section{Fibrosis as a Disease of Aging}

Fibrosis is a reparative response to injury culminating with the excessive deposition of extracellular matrix (ECM) proteins in tissues/organs. The process of fibrogenesis has been proposed to occur in four phases: primary injury driven response, activation of effector cells, and formation and remodeling of extracellular matrix components. ${ }^{101}$ Although fibrosis is a transient event in the normal wound healing process, ${ }^{102}$ persistent and/or progressive fibrosis with excess deposition of ECM leads eventually to organ failure and death. ${ }^{103}$

Fibrotic disease has been estimated to cause $45 \%$ of total mortality in the United States. ${ }^{102}$ Although pathological fibrosis can occur regardless of age, aging is known as one of the major risk factors in its development. ${ }^{104}$ The mechanism of age-associated fibrotic response is uncertain and could be attributed to genomic instability, telomere shortening, epigenetic changes, reduced autophagy, and mitochondrial dysfunction. ${ }^{104}$ Oxidative stress is known to be associated with age-related diseases, such as idiopathic pulmonary fibrosis (IPF). ${ }^{103}$ IPF affects approximately five million people worldwide, with 200,000 in the United States. ${ }^{105}$ IPF is the most fatal of the interstitial lung diseases, with a median survival of $<3$ years. ${ }^{106}$

The role of aging in IPF is incompletely understood. Exposure of lungs to various endogenous and exogenous oxidants may elicit inflammatory and fibrotic responses, leading to impaired antioxidant capacity. ${ }^{2}$ This may perpetuate the injury response and impede tissue regeneration with sustained fibrosis. This oxidant-antioxidant imbalance may be accentuated in aging.

After tissue injury, the up-regulation and activation of transforming growth factor- $\beta 1$ mediates differentiation of myofibroblasts, ${ }^{107}$ the main cells involved in connective tissue remodeling. ${ }^{108}$ Persistent activation of myofibroblasts with excess secretion of ECM proteins and enhanced contractility is associated with progressive fibrotic disorders, including IPF. ${ }^{108}$ Research from our group has revealed that activation of hydrogen peroxide-generating flavoenzyme NADPH oxidase (NOX4) mediates myofibroblast differentiation in response 
to transforming growth factor- $\beta .^{109}$ Since this report, several other studies have demonstrated a critical role of NOX4 in fibrosis involving the liver, ${ }^{110}$ kidney, ${ }^{111}$ and heart. ${ }^{112}$

More recent studies demonstrate that the up-regulation of NOX4 is coupled to Nrf2 induction, and this adaptive response is critical to apoptosis susceptibility of myofibroblasts and resolution of fibrosis in young mice. ${ }^{2}$ In contrast, in aged mice, there is impaired $\mathrm{Nrf} 2$ activation leading to an altered NOX4-Nrf2 redox balance and acquisition of an apoptosis-resistant myofibroblast phenotype resulting in persistent fibrosis. ${ }^{2}$ This supports a mechanism for the antagonistic pleotropic action of NOX4 that is determined by the activation. ${ }^{104}$

\section{Nrf2 in Age-Related Lung Fibrosis}

The reduced expression/activation of Nrf2 has been implicated in human and animal models of pulmonary fibrosis. ${ }^{2,113}$ Targeted deletion of Nrf2 in murine models of bleomycin-induced lung injury shows increased susceptibility to fibrosis with decreased ARE-mediated antioxidant gene expression. ${ }^{13}$ Bleomycin, cigarette smoke, and environmental oxidants augment oxidative injury in lungs deficient in Nrf2. ${ }^{114}$ Genetic ablation of Nrf2 decreases mRNA and protein expression of antioxidants, such as GST, NQO1, and HO-1, whereas the expression of genes encoding ECM and cytoskeletal proteins is induced in lungs of mice exposed to hyperoxia. ${ }^{115}$ Fibroblasts isolated from the lungs of injured aged mice and IPF reveal reduced expression of Nrf2 that promotes an apoptosis-resistant phenotype, ${ }^{2}$ and impaired capacity for myofibroblast dedifferentiation. ${ }^{116}$ Although the mechanism(s) for the reduced expression/activation of Nrf2 in aging is incompletely understood, alterations in redox sensing with aging may contribute to the aberrant cell phenotypes seen in progressive age-related fibrosis.

\section{Nrf2 as a Therapeutic Target}

The emergence of Nrf2 as a master regulator of multiple antioxidant and anti-inflammatory pathways in pathophysiological conditions has stimulated interest in Nrf2 as a therapeutic target. This is based on the concept that Nrf2 may mediate greater protection than an antioxidant strategy involving a single pathway (eg, augmenting glutathione levels with $\mathrm{N}$-acetylcysteine supplementation, which has shown to be ineffective in IPF). ${ }^{117}$ Various dietary phytochemicals, such as polyphenols, isothiocyanate, flavonoids, terpenoids, and synthetic chemical inducers, are known to induce Nrf2. Activation of Nrf2 by dietary phytochemicals and chemical inducer has been reported to mediate protective effects in certain cellular and animal models of disease. ${ }^{118,119} \mathrm{SFN}$, an organosulfur compound derived from cruciferous vegetables, is well-recognized for its robust action on induction of Nrf2. ${ }^{119}$ Activation of Nrf2 by SFN in IPF lung fibroblasts inhibited transforming growth factor$\beta$-induced profibrotic effects and induced myofibroblasts to dedifferentiate, ${ }^{116}$ an effect that may be important in fibrosis resolution. ${ }^{120}$ SFN-mediated activation of Nrf2 is also reported to reduce fibrosis in bleomycin mice model of lung fibrosis. ${ }^{35}$

Resveratrol, a naturally occurring phenolic phytochemical, modulates cellular homeostasis through the activation of the Nrf2 pathway. ${ }^{121}$ Activation of Nrf2 by resveratrol reduced paraquat-induced ROS-mediated inflammation and fibrotic reactions by up-regulation of cytoprotective genes in human bronchial epithelial cells. ${ }^{122}$ The mechanisms by which resveratrol activates Nrf2 are not well defined, but are unlikely to involve activation of sirtuins. ${ }^{69}$ Curcumin, a polyphenol obtained from rhizome of Curcuma Longa, has been shown to be an effective Nrf2 activator and inducer of Nrf2-dependent antioxidant and anti-inflammatory genes. ${ }^{123}$ In human monocytes, curcumin mediates the up-regulation of antioxidant defensive genes through Nrf2-ARE signaling via PKC and p38 mitogen-activated protein kinase. ${ }^{123}$ Curcumin ameliorated radiation-induced pulmonary fibrosis and enhanced the survival of mice in association with upregulation of antioxidant defenses in lungs. ${ }^{124}$ Quercetine, a dietary flavonoid found in citrus fruits, is another potential activator of Nrf2. Using ARE-luciferase reporter gene assays, quercetin has been shown to activate Nrf2 and upregulate NQO1. ${ }^{125}$ Quercetin-mediated Nrf2 nuclear translocation through p38 and extracellular signal regulated kinase signaling and induction of cytoprotective genes protects human hepatocytes against ethanol-derived oxidative stress. ${ }^{126}$ Exposure of NIH3T3 cells and human lung fibroblasts to quercetin induces the nuclear translocation of Nrf2, induces HO-1, and suppresses transforming growth factor$\beta$-simulated collagen synthesis. ${ }^{127}$

In addition to dietary compounds that are known to activate Nrf2, several chemical activators are being developed or are currently in clinical practice. An oral formulation of the chemical inducer dimethyl fumarate (commonly known as BG-132), US Food and Drug Administration approved for the treatment of multiple sclerosis, exerts antiinflammatory effects through the activation of the Nrf2 pathway. ${ }^{128}$ Dibenzoylmethane, an analog of curcumin, has been shown to activate the Nrf2-mediated detoxification pathway and inhibits benzo(a)pyrene-induced DNA adduct formation in lungs. ${ }^{129}$ Induction of Nrf2 with the triterpenoid CDDO-imidazolide (bardoxolone) and its analogs attenuates cigarette smoke-induced emphysema and cardiac dysfunction in mice, ${ }^{118}$ and diabetic nephropathy in preclinical models. ${ }^{130}$ However, in a recent phase II clinical trial of bardoxolone in chronic kidney disease, the study was terminated because of increased rate of heart-related adverse events, including heart failure, hospitalizations, and deaths. ${ }^{131}$ Whether this is because of off-target effects of this drug or because of unexpected potential detrimental effects of Nrf2 activation is not known. In recent years, efforts by pharmaceutical companies have focused on the development of novel Nrf2 activators to treat various chronic diseases, including lung fibrosis. It is anticipated 
that Nrf2 activators with greater specificity and efficacy will undergo clinical trials in the near future.

A potential dark side of $\mathrm{Nrf} 2$ has been highlighted in the progression of carcinogenesis. ${ }^{132}$ Although Nrf2 activation may be protective against cancer development in early stages, ${ }^{133}$ sustained or hyperactivation activation of Nrf2 with increased expression of cytoprotective genes enhanced cancer cell survival and conferred resistance to chemotherapy. ${ }^{133}$ Targeted deletion of Nrf2 reduced urethaneinduced tumorigenesis in lungs of mice by minimizing the expression of ARE-responsive genes. ${ }^{134}$ In addition, the tumor stroma has been reported to express high levels of Nrf2 and Nrf2 inhibitors proposed as an anticancer strategy. ${ }^{135}$ Hence, Nrf2 may represent double-edged sword, and this must be considered when administering Nrf2 activators as interventional drugs. Whether sustained or hyperactivation of Nrf2 in the context of fibrosis may predispose to cancer is unknown.

\section{Conclusions}

Accumulating evidence supports a role for deficient Nrf2 responses in several chronic age-related diseases, in particular fibrotic lung diseases. Although augmentation of Nrf2 may prove to be beneficial in lung fibrosis, it is important to recognize that such a strategy may mediate untoward effects because of the pleiotropic effects of Nrf2 and redox state on cellular signaling. Thus, it is important to define the context in which Nrf2 function is deficient or dysregulated before treatment of a particular disease can be targeted with Nrf2 activators. In addition, a more in-depth understanding of the mechanisms that lead to altered Nrf2 responses in aging and age-related fibrotic diseases is required; this will lead to more precise targeting approaches that are also likely to be safer and better tolerated.

\section{Acknowledgment}

We thank Naomi J. Logsdon for her valuable suggestions in editing the manuscript.

\section{References}

1. Thannickal VJ, Murthy M, Balch WE, Chandel NS, Meiners S, Eickelberg O, Selman M, Pardo A, White ES, Levy BD, Busse PJ, Tuder RM, Antony VB, Sznajder JI, Budinger GR: Blue journal conference: aging and susceptibility to lung disease. Am J Respir Crit Care Med 2015, 191:261-269

2. Hecker L, Logsdon NJ, Kurundkar D, Kurundkar A, Bernard K, Hock T, Meldrum E, Sanders YY, Thannickal VJ: Reversal of persistent fibrosis in aging by targeting Nox4-Nrf2 redox imbalance. Sci Transl Med 2014, 6:231ra247

3. Al-Sawaf O, Clarner T, Fragoulis A, Kan YW, Pufe T, Streetz K, Wruck CJ: Nrf2 in health and disease: current and future clinical implications. Clin Sci (Lond) 2015, 129:989-999

4. Jaramillo MC, Zhang DD: The emerging role of the Nrf2-Keap1 signaling pathway in cancer. Genes Dev 2013, 27:2179-2191
5. Zhang DD, Lo SC, Cross JV, Templeton DJ, Hannink M: Keap1 is a redox-regulated substrate adaptor protein for a Cul3-dependent ubiquitin ligase complex. Mol Cell Biol 2004, 24:10941-10953

6. McMahon M, Thomas N, Itoh K, Yamamoto M, Hayes JD: Dimerization of substrate adaptors can facilitate cullin-mediated ubiquitylation of proteins by a "tethering" mechanism: a two-site interaction model for the Nrf2-Keap1 complex. J Biol Chem 2006, 281:24756-24768

7. Nioi P, Nguyen T, Sherratt PJ, Pickett CB: The carboxy-terminal Neh3 domain of Nrf2 is required for transcriptional activation. Mol Cell Biol 2005, 25:10895-10906

8. Katoh Y, Itoh K, Yoshida E, Miyagishi M, Fukamizu A, Yamamoto M: Two domains of Nrf2 cooperatively bind CBP, a CREB binding protein, and synergistically activate transcription. Genes Cells 2001, 6:857-868

9. Moi P, Chan K, Asunis I, Cao A, Kan YW: Isolation of NF-E2related factor 2 (Nrf2), a NF-E2-like basic leucine zipper transcriptional activator that binds to the tandem NF-E2/AP1 repeat of the beta-globin locus control region. Proc Natl Acad Sci U S A 1994, 91 : 9926-9930

10. McMahon M, Thomas N, Itoh K, Yamamoto M, Hayes JD: Redoxregulated turnover of Nrf2 is determined by at least two separate protein domains, the redox-sensitive Neh2 degron and the redoxinsensitive Neh6 degron. J Biol Chem 2004, 279:31556-31567

11. Wang H, Liu K, Geng M, Gao P, Wu X, Hai Y, Li Y, Luo L, Hayes JD, Wang XJ, Tang X: RXRalpha inhibits the NRF2-ARE signaling pathway through a direct interaction with the Neh7 domain of NRF2. Cancer Res 2013, 73:3097-3108

12. Dhakshinamoorthy S, Jaiswal AK: Functional characterization and role of INrf2 in antioxidant response element-mediated expression and antioxidant induction of $\mathrm{NAD}(\mathrm{P}) \mathrm{H}$ :quinone oxidoreductase 1 gene. Oncogene 2001, 20:3906-3917

13. Ogura T, Tong KI, Mio K, Maruyama Y, Kurokawa H, Sato C, Yamamoto M: Keap1 is a forked-stem dimer structure with two large spheres enclosing the intervening, double glycine repeat, and C-terminal domains. Proc Natl Acad Sci U S A 2010, 107: $2842-2847$

14. Zhang DD, Hannink M: Distinct cysteine residues in Keap1 are required for Keap1-dependent ubiquitination of Nrf2 and for stabilization of Nrf2 by chemopreventive agents and oxidative stress. Mol Cell Biol 2003, 23:8137-8151

15. Niture SK, Jain AK, Jaiswal AK: Antioxidant-induced modification of INrf2 cysteine 151 and PKC-delta-mediated phosphorylation of Nrf2 serine 40 are both required for stabilization and nuclear translocation of Nrf2 and increased drug resistance. J Cell Sci 2009, 122: $4452-4464$

16. Chanas SA, Jiang Q, McMahon M, McWalter GK, McLellan LI, Elcombe CR, Henderson CJ, Wolf CR, Moffat GJ, Itoh K, Yamamoto M, Hayes JD: Loss of the Nrf2 transcription factor causes a marked reduction in constitutive and inducible expression of the glutathione S-transferase Gsta1, Gsta2, Gstm1, Gstm2, Gstm3 and Gstm4 genes in the livers of male and female mice. Biochem J 2002, 365:405-416

17. Thimmulappa RK, Mai KH, Srisuma S, Kensler TW, Yamamoto M, Biswal S: Identification of Nrf2-regulated genes induced by the chemopreventive agent sulforaphane by oligonucleotide microarray. Cancer Res 2002, 62:5196-5203

18. Nioi P, Hayes JD: Contribution of $\mathrm{NAD}(\mathrm{P}) \mathrm{H}$ :quinone oxidoreductase 1 to protection against carcinogenesis, and regulation of its gene by the Nrf2 basic-region leucine zipper and the arylhydrocarbon receptor basic helix-loop-helix transcription factors. Mutat Res 2004, 555: $149-171$

19. Alam J, Wicks C, Stewart D, Gong P, Touchard C, Otterbein S, Choi AM, Burow ME, Tou J: Mechanism of heme oxygenase-1 gene activation by cadmium in MCF-7 mammary epithelial cells: role of p38 kinase and Nrf2 transcription factor. J Biol Chem 2000, 275 : 27694-27702 
20. Chorley BN, Campbell MR, Wang X, Karaca M, Sambandan D, Bangura F, Xue P, Pi J, Kleeberger SR, Bell DA: Identification of novel NRF2-regulated genes by ChIP-Seq: influence on retinoid X receptor alpha. Nucleic Acids Res 2012, 40: $7416-7429$

21. Wu KC, Cui JY, Klaassen CD: Beneficial role of Nrf2 in regulating NADPH generation and consumption. Toxicol Sci 2011, 123: 590-600

22. Malhotra D, Portales-Casamar E, Singh A, Srivastava S, Arenillas D, Happel C, Shyr C, Wakabayashi N, Kensler TW, Wasserman WW, Biswal S: Global mapping of binding sites for Nrf2 identifies novel targets in cell survival response through ChIP-Seq profiling and network analysis. Nucleic Acids Res 2010, 38:5718-5734

23. Jain A, Lamark T, Sjottem E, Larsen KB, Awuh JA, Overvatn A, McMahon M, Hayes JD, Johansen T: p62/SQSTM1 is a target gene for transcription factor NRF2 and creates a positive feedback loop by inducing antioxidant response element-driven gene transcription. J Biol Chem 2010, 285:22576-22591

24. Xu IM, Lai RK, Lin SH, Tse AP, Chiu DK, Koh HY, Law CT, Wong CM, Cai Z, Wong CC, Ng IO: Transketolase counteracts oxidative stress to drive cancer development. Proc Natl Acad Sci U S A 2016, 113:E725-E734

25. Zhang H, Court N, Forman HJ: Submicromolar concentrations of 4-hydroxynonenal induce glutamate cysteine ligase expression in HBE1 cells. Redox Rep 2007, 12:101-106

26. Ishii $\mathrm{T}$, Itoh $\mathrm{K}$, Takahashi $\mathrm{S}$, Sato $\mathrm{H}$, Yanagawa $\mathrm{T}$, Katoh $\mathrm{Y}$, Bannai S, Yamamoto M: Transcription factor Nrf2 coordinately regulates a group of oxidative stress-inducible genes in macrophages. J Biol Chem 2000, 275:16023-16029

27. Liu X, Ward K, Xavier C, Jann J, Clark AF, Pang IH, Wu H: The novel triterpenoid RTA 408 protects human retinal pigment epithelial cells against HO-induced cell injury via NF-E2-related factor 2 (Nrf2) activation. Redox Biol 2015, 8:98-109

28. Thimmulappa RK, Lee H, Rangasamy T, Reddy SP, Yamamoto M, Kensler TW, Biswal S: Nrf2 is a critical regulator of the innate immune response and survival during experimental sepsis. J Clin Invest 2006, 116:984-995

29. Wardyn Joanna D, Ponsford Amy H, Sanderson Christopher M: Dissecting molecular cross-talk between Nrf2 and NF- $\mathrm{BB}$ response pathways. Biochem Soc Trans 2015, 43:621-626

30. Li B, Abdalrahman A, Lai Y, Janicki JS, Ward KW, Meyer CJ, Wang XL, Tang D, Cui T: Dihydro-CDDO-trifluoroethyl amide suppresses inflammatory responses in macrophages via activation of Nrf2. Biochem Biophys Res Commun 2014, 444:555-561

31. Braun S, Hanselmann C, Gassmann MG, auf dem Keller U, BornBerclaz C, Chan K, Kan YW, Werner S: Nrf2 transcription factor, a novel target of keratinocyte growth factor action which regulates gene expression and inflammation in the healing skin wound. Mol Cell Biol 2002, 22:5492-5505

32. Rojo AI, McBean G, Cindric M, Egea J, Lopez MG, Rada P, Zarkovic N, Cuadrado A: Redox control of microglial function: molecular mechanisms and functional significance. Antioxid Redox Signal 2014, 21:1766-1801

33. O'Brien ML, Tew KD: Glutathione and related enzymes in multidrug resistance. Eur J Cancer 1996, 32a:967-978

34. Higgins LG, Kelleher MO, Eggleston IM, Itoh K, Yamamoto M, Hayes JD: Transcription factor Nrf2 mediates an adaptive response to sulforaphane that protects fibroblasts in vitro against the cytotoxic effects of electrophiles, peroxides and redox-cycling agents. Toxicol Appl Pharmacol 2009, 237:267-280

35. Pekovic-Vaughan V, Gibbs J, Yoshitane H, Yang N, Pathiranage D, Guo B, Sagami A, Taguchi K, Bechtold D, Loudon A, Yamamoto M, Chan J, van der Horst GT, Fukada Y, Meng QJ: The circadian clock regulates rhythmic activation of the NRF2/glutathione-mediated antioxidant defense pathway to modulate pulmonary fibrosis. Genes Dev 2014, 28:548-560
36. Xu YQ, Zhang D, Jin T, Cai DJ, Wu Q, Lu Y, Liu J, Klaassen CD: Diurnal variation of hepatic antioxidant gene expression in mice. PLoS One 2012, 7:e44237

37. Rebrin I, Kamzalov S, Sohal RS: Effects of age and caloric restriction on glutathione redox state in mice. Free Radic Biol Med 2003, 35: 626-635

38. Alam J, Stewart D, Touchard C, Boinapally S, Choi AM, Cook JL: Nrf2, a Cap'n'Collar transcription factor, regulates induction of the heme oxygenase-1 gene. J Biol Chem 1999, 274:26071-26078

39. Patil K, Bellner L, Cullaro G, Gotlinger KH, Dunn MW, Schwartzman ML: Heme oxygenase-1 induction attenuates corneal inflammation and accelerates wound healing after epithelial injury. Invest Ophthalmol Vis Sci 2008, 49:3379-3386

40. Soares MP, Seldon MP, Gregoire IP, Vassilevskaia T, Berberat PO, Yu J, Tsui TY, Bach FH: Heme oxygenase-1 modulates the expression of adhesion molecules associated with endothelial cell activation. J Immunol 2004, 172:3553-3563

41. Lin W, Wu RT, Wu T, Khor TO, Wang H, Kong AN: Sulforaphane suppressed LPS-induced inflammation in mouse peritoneal macrophages through Nrf2 dependent pathway. Biochem Pharmacol 2008, 76:967-973

42. Reddy NM, Potteti HR, Mariani TJ, Biswal S, Reddy SP: Conditional deletion of Nrf2 in airway epithelium exacerbates acute lung injury and impairs the resolution of inflammation. Am J Respir Cell Mol Biol 2011, 45:1161-1168

43. Hayes JD, Dinkova-Kostova AT: The Nrf2 regulatory network provides an interface between redox and intermediary metabolism. Trends Biochem Sci 2014, 39:199-218

44. Pickering AM, Linder RA, Zhang H, Forman HJ, Davies KJ: Nrf2dependent induction of proteasome and Pa28alphabeta regulator are required for adaptation to oxidative stress. J Biol Chem 2012, 287: 10021-10031

45. Kwak MK, Wakabayashi N, Greenlaw JL, Yamamoto M Kensler TW: Antioxidants enhance mammalian proteasome expression through the Keap1-Nrf2 signaling pathway. Mol Cell Biol 2003, 23:8786-8794

46. Singh B, Chatterjee A, Ronghe AM, Bhat NK, Bhat HK: Antioxidant-mediated up-regulation of OGG1 via NRF2 induction is associated with inhibition of oxidative DNA damage in estrogen-induced breast cancer. BMC Cancer 2013, 13:253

47. Holmstrom KM, Baird L, Zhang Y, Hargreaves I, Chalasani A, Land JM, Stanyer L, Yamamoto M, Dinkova-Kostova AT, Abramov AY: Nrf2 impacts cellular bioenergetics by controlling substrate availability for mitochondrial respiration. Biol Open 2013, 2:761-770

48. Ludtmann MH, Angelova PR, Zhang Y, Abramov AY, DinkovaKostova AT: Nrf2 affects the efficiency of mitochondrial fatty acid oxidation. Biochem J 2014, 457:415-424

49. Richardson AG, Schadt EE: The role of macromolecular damage in aging and age-related disease. J Gerontol A Biol Sci Med Sci 2014, 69:S28-S32

50. Finkel T, Holbrook NJ: Oxidants, oxidative stress and the biology of ageing. Nature 2000, 408:239-247

51. Thannickal VJ, Fanburg BL: Reactive oxygen species in cell signaling. Am J Physiol Lung Cell Mol Physiol 2000, 279: L1005-L1028

52. Zhang Y, Ikeno Y, Qi W, Chaudhuri A, Li Y, Bokov A, Thorpe SR, Baynes JW, Epstein C, Richardson A, Van Remmen H: Mice deficient in both $\mathrm{Mn}$ superoxide dismutase and glutathione peroxidase-1 have increased oxidative damage and a greater incidence of pathology but no reduction in longevity. J Gerontol A Biol Sci Med Sci 2009, 64:1212-1220

53. Perez VI, Van Remmen H, Bokov A, Epstein CJ, Vijg J, Richardson A: The overexpression of major antioxidant enzymes does not extend the lifespan of mice. Aging Cell 2009, 8:73-75

54. Lewis KN, Wason E, Edrey YH, Kristan DM, Nevo E, Buffenstein R: Regulation of Nrf2 signaling and longevity in naturally long-lived rodents. Proc Natl Acad Sci U S A 2015, 112:3722-3727 
55. Sykiotis GP, Bohmann D: Keap1/Nrf2 signaling regulates oxidative stress tolerance and lifespan in Drosophila. Dev Cell 2008, 14: $76-85$

56. Tsakiri EN, Sykiotis GP, Papassideri IS, Terpos E, Dimopoulos MA, Gorgoulis VG, Bohmann D, Trougakos IP: Proteasome dysfunction in Drosophila signals to an Nrf2-dependent regulatory circuit aiming to restore proteostasis and prevent premature aging. Aging Cell 2013, $12: 802-813$

57. Blackwell TK, Steinbaugh MJ, Hourihan JM, Ewald CY, Isik M: SKN-1/Nrf, stress responses, and aging in Caenorhabditis elegans. Free Radic Biol Med 2015, 88:290-301

58. Ewald CY, Landis JN, Porter Abate J, Murphy CT, Blackwell TK: Dauer-independent insulin/IGF-1-signalling implicates collagen remodelling in longevity. Nature 2015, 519:97-101

59. Sykiotis GP, Bohmann D: Stress-activated cap'n'collar transcription factors in aging and human disease. Sci Signal 2010, 3:re3

60. Shih PH, Yen GC: Differential expressions of antioxidant status in aging rats: the role of transcriptional factor Nrf2 and MAPK signaling pathway. Biogerontology 2007, 8:71-80

61. Ungvari Z, Bailey-Downs L, Sosnowska D, Gautam T, Koncz P, Losonczy G, Ballabh P, de Cabo R, Sonntag WE, Csiszar A: Vascular oxidative stress in aging: a homeostatic failure due to dysregulation of NRF2-mediated antioxidant response. Am J Physiol Heart Circ Physiol 2011, 30:H363-H372

62. Suh JH, Shenvi SV, Dixon BM, Liu H, Jaiswal AK, Liu RM, Hagen TM: Decline in transcriptional activity of Nrf2 causes agerelated loss of glutathione synthesis, which is reversible with lipoic acid. Proc Natl Acad Sci U S A 2004, 101:3381-3386

63. Kang MI, Kobayashi A, Wakabayashi N, Kim SG, Yamamoto M: Scaffolding of Keap1 to the actin cytoskeleton controls the function of Nrf2 as key regulator of cytoprotective phase 2 genes. Proc Natl Acad Sci U S A 2004, 101:2046-2051

64. Lim IK, Won Hong K, Kwak IH, Yoon G, Park SC: Cytoplasmic retention of $\mathrm{p}$-Erk1/2 and nuclear accumulation of actin proteins during cellular senescence in human diploid fibroblasts. Mech Ageing Dev 2000, 119:113-130

65. Chen W, Sun Z, Wang XJ, Jiang T, Huang Z, Fang D, Zhang DD: Direct interaction between Nrf2 and p21(Cip1/WAF1) upregulates the Nrf2-mediated antioxidant response. Mol Cell 2009, 34:663-673

66. Cui J, Bai XY, Shi S, Cui S, Hong Q, Cai G, Chen X: Age-related changes in the function of autophagy in rat kidneys. Age (Dordr) 2012, 34:329-339

67. Lau A, Wang XJ, Zhao F, Villeneuve NF, Wu T, Jiang T, Sun Z, White E, Zhang DD: A noncanonical mechanism of Nrf2 activation by autophagy deficiency: direct interaction between Keap1 and p62. Mol Cell Biol 2010, 30:3275-3285

68. Bartlett BJ, Isakson P, Lewerenz J, Sanchez H, Kotzebue RW, Cumming RC, Harris GL, Nezis IP, Schubert DR, Simonsen A, Finley KD: p62, $\operatorname{Ref}(2) \mathrm{P}$ and ubiquitinated proteins are conserved markers of neuronal aging, aggregate formation and progressive autophagic defects. Autophagy 2011, 7:572-583

69. Kawai Y, Garduno L, Theodore M, Yang J, Arinze IJ: Acetylationdeacetylation of the transcription factor Nrf2 (nuclear factor erythroid 2-related factor 2) regulates its transcriptional activity and nucleocytoplasmic localization. J Biol Chem 2011, 286:7629-7640

70. Sun Z, Chin YE, Zhang DD: Acetylation of Nrf2 by p300/CBP augments promoter-specific DNA binding of Nrf2 during the antioxidant response. Mol Cell Biol 2009, 29:2658-2672

71. Hirotsu Y, Katsuoka F, Funayama R, Nagashima T, Nishida Y, Nakayama K, Engel JD, Yamamoto M: Nrf2-MafG heterodimers contribute globally to antioxidant and metabolic networks. Nucleic Acids Res 2012, 40:10228-10239

72. Miyamoto N, Izumi H, Miyamoto R, Bin H, Kondo H, Tawara A, Sasaguri Y, Kohno K: Transcriptional regulation of activating transcription factor 4 under oxidative stress in retinal pigment epithelial ARPE-19/HPV-16 cells. Invest Ophthalmol Vis Sci 2011, 52: $1226-1234$
73. Mylroie H, Dumont O, Bauer A, Thornton CC, Mackey J, Calay D, Hamdulay SS, Choo JR, Boyle JJ, Samarel AM, Randi AM, Evans PC, Mason JC: PKCepsilon-CREB-Nrf2 signalling induces HO-1 in the vascular endothelium and enhances resistance to inflammation and apoptosis. Cardiovasc Res 2015, 106:509-519

74. Huang HC, Nguyen T, Pickett CB: Regulation of the antioxidant response element by protein kinase C-mediated phosphorylation of NF-E2-related factor 2. Proc Natl Acad Sci U S A 2000, 97: $12475-12480$

75. Numazawa S, Ishikawa M, Yoshida A, Tanaka S, Yoshida T: Atypical protein kinase $\mathrm{C}$ mediates activation of NF-E2-related factor 2 in response to oxidative stress. Am J Physiol Cell Physiol 2003, 285:C334-C342

76. Nakaso K, Yano H, Fukuhara Y, Takeshima T, Wada-Isoe K, Nakashima K: PI3K is a key molecule in the Nrf2-mediated regulation of antioxidative proteins by hemin in human neuroblastoma cells. FEBS Lett 2003, 546:181-184

77. Zipper LM, Mulcahy RT: Erk activation is required for Nrf2 nuclear localization during pyrrolidine dithiocarbamate induction of glutamate cysteine ligase modulatory gene expression in HepG2 cells. Toxicol Sci 2003, 73:124-134

78. Vari R, D'Archivio M, Filesi C, Carotenuto S, Scazzocchio B, Santangelo C, Giovannini C, Masella R: Protocatechuic acid induces antioxidant/detoxifying enzyme expression through JNK-mediated Nrf2 activation in murine macrophages. J Nutr Biochem 2011, 22: 409-417

79. Jain AK, Jaiswal AK: GSK-3beta acts upstream of Fyn kinase in regulation of nuclear export and degradation of NF-E2 related factor 2. J Biol Chem 2007, 282:16502-16510

80. Facchinetti MM, de Boland AR: Effect of ageing on the expression of protein kinase $\mathrm{C}$ and its activation by $1,25(\mathrm{OH}) 2$-vitamin $\mathrm{D} 3$ in rat skeletal muscle. Cell Signal 1999, 11:39-44

81. Takahashi H, Okamura D, Starr ME, Saito H, Evers BM: Agedependent reduction of the PI3K regulatory subunit p85alpha suppresses pancreatic acinar cell proliferation. Aging Cell 2012, 11: 305-314

82. Dhakshinamoorthy S, Jain AK, Bloom DA, Jaiswal AK: Bach1 competes with $\mathrm{Nrf} 2$ leading to negative regulation of the antioxidant response element (ARE)-mediated $\mathrm{NAD}(\mathrm{P}) \mathrm{H}$ :quinone oxidoreductase 1 gene expression and induction in response to antioxidants. J Biol Chem 2005, 280:16891-16900

83. Shenvi SV, Smith E, Hagen TM: Identification of age-specific Nrf2 binding to a novel antioxidant response element locus in the Gclc promoter: a compensatory means for the loss of glutathione synthetic capacity in the aging rat liver? Aging Cell 2012, 11:297-304

84. Rahman MM, Sykiotis GP, Nishimura M, Bodmer R, Bohmann D: Declining signal dependence of Nrf2-MafS-regulated gene expression correlates with aging phenotypes. Aging Cell 2013, 12:554-562

85. He CH, Gong P, Hu B, Stewart D, Choi ME, Choi AM, Alam J: Identification of activating transcription factor 4 (ATF4) as an Nrf2interacting protein: implication for heme oxygenase-1 gene regulation. J Biol Chem 2001, 276:20858-20865

86. Hussain SG, Ramaiah KV: Reduced eIF2alpha phosphorylation and increased proapoptotic proteins in aging. Biochem Biophys Res Commun 2007, 355:365-370

87. Im JY, Lee KW, Woo JM, Junn E, Mouradian MM: DJ-1 induces thioredoxin 1 expression through the Nrf2 pathway. Hum Mol Genet 2012, 21:3013-3024

88. O'Connell MA, Hayes JD: The Keap1/Nrf2 pathway in health and disease: from the bench to the clinic. Biochem Soc Trans 2015, 43 : 687-689

89. Wu T, Zhao F, Gao B, Tan C, Yagishita N, Nakajima T, Wong PK, Chapman E, Fang D, Zhang DD: Hrd1 suppresses Nrf2-mediated cellular protection during liver cirrhosis. Genes Dev 2014, 28: 708-722

90. Rada P, Rojo AI, Chowdhry S, McMahon M, Hayes JD, Cuadrado A: $\mathrm{SCF} /\{$ beta\}-TrCP promotes glycogen synthase kinase 3-dependent 
degradation of the Nrf2 transcription factor in a Keap1-independent manner. Mol Cell Biol 2011, 31:1121-1133

91. Liu XM, Peyton KJ, Shebib AR, Wang H, Korthuis RJ, Durante W: Activation of AMPK stimulates heme oxygenase-1 gene expression and human endothelial cell survival. Am J Physiol Heart Circ Physiol 2011, 300:H84-H93

92. Tomasi ML, Ryoo M, Yang H, Iglesias Ara A, Ko KS, Lu SC: Molecular mechanisms of lipopolysaccharide-mediated inhibition of glutathione synthesis in mice. Free Radic Biol Med 2014, 68: $148-158$

93. Narasimhan M, Patel D, Vedpathak D, Rathinam M, Henderson G, Mahimainathan L: Identification of novel microRNAs in posttranscriptional control of Nrf2 expression and redox homeostasis in neuronal, SH-SY5Y cells. PLoS One 2012, 7:e51111

94. Zimmermann K, Baldinger J, Mayerhofer B, Atanasov AG, Dirsch VM, Heiss EH: Activated AMPK boosts the Nrf2/HO-1 signaling axis-A role for the unfolded protein response. Free Radic Biol Med 2015, 88:417-426

95. Sapir A, Tsur A, Koorman T, Ching K, Mishra P, Bardenheier A, Podolsky L, Bening-Abu-Shach U, Boxem M, Chou TF, Broday L, Sternberg PW: Controlled sumoylation of the mevalonate pathway enzyme HMGS-1 regulates metabolism during aging. Proc Natl Acad Sci U S A 2014, 111:E3880-E3889

96. Gao Y, Yan Y, Huang T: Human age related cataracts: epigenetic suppression of the nuclear factor erythroid 2 related factor 2 mediated antioxidant system. Mol Med Rep 2015, 11:1442-1447

97. Inukai S, Slack F: MicroRNAs and the genetic network in aging. J Mol Biol 2013, 425:3601-3608

98. Yang JJ, Tao H, Hu W, Liu LP, Shi KH, Deng ZY, Li J: MicroRNA200a controls Nrf2 activation by target Keap1 in hepatic stellate cell proliferation and fibrosis. Cell Signal 2014, 26:2381-2389

99. Yu S, Khor TO, Cheung KL, Li W, Wu TY, Huang Y, Foster BA, Kan YW, Kong AN: Nrf2 expression is regulated by epigenetic mechanisms in prostate cancer of TRAMP mice. PLoS One 2010, 5: e8579

100. Belden WJ, Dunlap JC: Aging well with a little wine and a good clock. Cell 2013, 153:1421-1422

101. Rockey DC, Bell PD, Hill JA: Fibrosis: a common pathway to organ injury and failure. N Engl J Med 2015, 372:1138-1149

102. Thannickal VJ, Zhou Y, Gaggar A, Duncan SR: Fibrosis: ultimate and proximate causes. J Clin Invest 2014, 124:4673-4677

103. Thannickal VJ, Toews GB, White ES, Lynch JP 3rd, Martinez FJ: Mechanisms of pulmonary fibrosis. Annu Rev Med 2004, 55: 395-417

104. Thannickal VJ: Mechanistic links between aging and lung fibrosis. Biogerontology 2013, 14:609-615

105. Raghu G, Weycker D, Edelsberg J, Bradford WZ, Oster G: Incidence and prevalence of idiopathic pulmonary fibrosis. Am J Respir Crit Care Med 2006, 174:810-816

106. Schwartz DA, Helmers RA, Galvin JR, Van Fossen DS, Frees KL, Dayton CS, Burmeister LF, Hunninghake GW: Determinants of survival in idiopathic pulmonary fibrosis. Am J Respir Crit Care Med 1994, 149:450-454

107. Border WA, Noble NA: Transforming growth factor beta in tissue fibrosis. N Engl J Med 1994, 331:1286-1292

108. Tomasek JJ, Gabbiani G, Hinz B, Chaponnier C, Brown RA: Myofibroblasts and mechano-regulation of connective tissue remodelling. Nat Rev Mol Cell Biol 2002, 3:349-363

109. Hecker L, Vittal R, Jones T, Jagirdar R, Luckhardt TR, Horowitz JC, Pennathur S, Martinez FJ, Thannickal VJ: NADPH oxidase-4 mediates myofibroblast activation and fibrogenic responses to lung injury. Nat Med 2009, 15:1077-1081

110. Jiang JX, Chen X, Serizawa N, Szyndralewiez C, Page P, Schroder K, Brandes RP, Devaraj S, Torok NJ: Liver fibrosis and hepatocyte apoptosis are attenuated by GKT137831, a novel NOX4/NOX1 inhibitor in vivo. Free Radic Biol Med 2012, 53: 289-296
111. Bondi CD, Manickam N, Lee DY, Block K, Gorin Y, Abboud HE, Barnes JL: NAD(P)H oxidase mediates TGF-beta1-induced activation of kidney myofibroblasts. J Am Soc Nephrol 2010, 21:93-102

112. Kuroda J, Ago T, Matsushima S, Zhai P, Schneider MD, Sadoshima J: NADPH oxidase 4 (Nox4) is a major source of oxidative stress in the failing heart. Proc Natl Acad Sci U S A 2010, 107:15565-15570

113. Cho HY, Reddy SP, Yamamoto M, Kleeberger SR: The transcription factor NRF2 protects against pulmonary fibrosis. FASEB J 2004, 18: $1258-1260$

114. Cho HY, Reddy SP, Kleeberger SR: Nrf2 defends the lung from oxidative stress. Antioxid Redox Signal 2006, 8:76-87

115. Cho HY, Reddy SP, Debiase A, Yamamoto M, Kleeberger SR: Gene expression profiling of NRF2-mediated protection against oxidative injury. Free Radic Biol Med 2005, 38:325-343

116. Artaud-Macari E, Goven D, Brayer S, Hamimi A, Besnard V, Marchal-Somme J, Ali ZE, Crestani B, Kerdine-Romer S, Boutten A, Bonay M: Nuclear factor erythroid 2-related factor 2 nuclear translocation induces myofibroblastic dedifferentiation in idiopathic pulmonary fibrosis. Antioxid Redox Signal 2013, 18:66-79

117. Martinez FJ, de Andrade JA, Anstrom KJ, King TE Jr, Raghu G: Randomized trial of acetylcysteine in idiopathic pulmonary fibrosis. N Engl J Med 2014, 370:2093-2101

118. Sussan TE, Rangasamy T, Blake DJ, Malhotra D, El-Haddad H, Bedja D, Yates MS, Kombairaju P, Yamamoto M, Liby KT, Sporn MB, Gabrielson KL, Champion HC, Tuder RM, Kensler TW, Biswal S: Targeting Nrf2 with the triterpenoid CDDO-imidazolide attenuates cigarette smoke-induced emphysema and cardiac dysfunction in mice. Proc Natl Acad Sci U S A 2009, 106:250-255

119. Tarozzi A, Angeloni C, Malaguti M, Morroni F, Hrelia S, Hrelia P: Sulforaphane as a potential protective phytochemical against neurodegenerative diseases. Oxid Med Cell Longev 2013, 2013:415078

120. Hecker L, Jagirdar R, Jin T, Thannickal VJ: Reversible differentiation of myofibroblasts by MyoD. Exp Cell Res 2011, 317:1914-1921

121. Ungvari Z, Bagi Z, Feher A, Recchia FA, Sonntag WE, Pearson K, de Cabo R, Csiszar A: Resveratrol confers endothelial protection via activation of the antioxidant transcription factor Nrf2. Am J Physiol Heart Circ Physiol 2010, 299:H18-H24

122. He X, Wang L, Szklarz G, Bi Y, Ma Q: Resveratrol inhibits paraquatinduced oxidative stress and fibrogenic response by activating the nuclear factor erythroid 2-related factor 2 pathway. J Pharmacol Exp Ther 2012, 342:81-90

123. Tapia E, Soto V, Ortiz-Vega KM, Zarco-Marquez G, Molina-Jijon E, Cristobal-Garcia M, Santamaria J, Garcia-Nino WR, Correa F, Zazueta C, Pedraza-Chaverri J: Curcumin induces Nrf2 nuclear translocation and prevents glomerular hypertension, hyperfiltration, oxidant stress, and the decrease in antioxidant enzymes in $5 / 6$ nephrectomized rats. Oxid Med Cell Longev 2012, 2012:269039

124. Lee JC, Kinniry PA, Arguiri E, Serota M, Kanterakis S, Chatterjee S, Solomides CC, Javvadi P, Koumenis C, Cengel KA, ChristofidouSolomidou M: Dietary curcumin increases antioxidant defenses in lung, ameliorates radiation-induced pulmonary fibrosis, and improves survival in mice. Radiat Res 2010, 173:590-601

125. Tanigawa S, Fujii M, Hou DX: Action of Nrf2 and Keap1 in AREmediated NQO1 expression by quercetin. Free Radic Biol Med 2007, 42:1690-1703

126. Yao P, Nussler A, Liu L, Hao L, Song F, Schirmeier A, Nussler N: Quercetin protects human hepatocytes from ethanol-derived oxidative stress by inducing heme oxygenase-1 via the MAPK/Nrf2 pathways. J Hepatol 2007, 47:253-261

127. Nakamura T, Matsushima M, Hayashi Y, Shibasaki M, Imaizumi K, Hashimoto N, Shimokata K, Hasegawa Y, Kawabe T: Attenuation of transforming growth factor-beta-stimulated collagen production in fibroblasts by quercetin-induced heme oxygenase-1. Am J Respir Cell Mol Biol 2011, 44:614-620

128. Lin SX, Lisi L, Dello Russo C, Polak PE, Sharp A, Weinberg G, Kalinin S, Feinstein DL: The anti-inflammatory effects of dimethyl 
fumarate in astrocytes involve glutathione and haem oxygenase-1. ASN Neuro 2011, 3:e00055

129. Thimmulappa RK, Rangasamy T, Alam J, Biswal S: Dibenzoylmethane activates Nrf2-dependent detoxification pathway and inhibits benzo(a) pyrene induced DNA adducts in lungs. Med Chem 2008, 4:473-481

130. Tan SM, Sharma A, Stefanovic N, Yuen DY, Karagiannis TC, Meyer C, Ward KW, Cooper ME, de Haan JB: Derivative of bardoxolone methyl, dh404, in an inverse dose-dependent manner lessens diabetes-associated atherosclerosis and improves diabetic kidney disease. Diabetes 2014, 63:3091-3103

131. de Zeeuw D, Akizawa T, Audhya P, Bakris GL, Chin M, ChristSchmidt H, Goldsberry A, Houser M, Krauth M, Lambers Heerspink HJ, McMurray JJ, Meyer CJ, Parving HH, Remuzzi G, Toto RD, Vaziri ND, Wanner C, Wittes J, Wrolstad D, Chertow GM: Bardoxolone methyl in type 2 diabetes and stage 4 chronic kidney disease. N Engl J Med 2013, 369:2492-2503
132. Wang XJ, Sun Z, Villeneuve NF, Zhang S, Zhao F, Li Y, Chen W, Yi X, Zheng W, Wondrak GT, Wong PK, Zhang DD: Nrf2 enhances resistance of cancer cells to chemotherapeutic drugs, the dark side of Nrf2. Carcinogenesis 2008, 29:1235-1243

133. Satoh H, Moriguchi T, Takai J, Ebina M, Yamamoto M: Nrf2 prevents initiation but accelerates progression through the Kras signaling pathway during lung carcinogenesis. Cancer Res 2013, 73: 4158-4168

134. Bauer AK, Cho HY, Miller-Degraff L, Walker C, Helms K, Fostel J, Yamamoto M, Kleeberger SR: Targeted deletion of Nrf2 reduces urethane-induced lung tumor development in mice. PLoS One 2011, 6:e26590

135. Ren D, Villeneuve NF, Jiang $\mathrm{T}$, Wu $\mathrm{T}$, Lau A, Toppin HA, Zhang DD: Brusatol enhances the efficacy of chemotherapy by inhibiting the Nrf2-mediated defense mechanism. Proc Natl Acad Sci U S A 2011, 108:1433-1438 